\section{(6) OPEN ACCESS}

\title{
Does legislation to prevent alcohol sales to drunk individuals work? Measuring the propensity for night-time sales to drunks in a UK city
}

\author{
Karen Hughes, ${ }^{1}$ Mark A Bellis, ${ }^{1,2}$ Nicola Leckenby, ${ }^{1}$ Zara Quigg, ${ }^{1}$ \\ Katherine Hardcastle, ${ }^{1}$ Olivia Sharples, ${ }^{1}$ David J Llewellyn ${ }^{3}$
}

${ }^{1}$ Centre for Public Health, WHO Collaborating Centre for Violence Prevention, Liverpool John Moores University,

Liverpool, UK

2Public Health Wales, Hadyn

Ellis Building, Cardiff, UK

${ }^{3}$ Liverpool Screen School,

Liverpool John Moores

University, The Joe H Makin

Drama Centre, Liverpool, UK

\section{Correspondence to}

Professor Mark A Bellis, Centre for Public Health, WHO

Collaborating Centre for Violence Prevention, Liverpool John Moores University, 1521 Webster Street, Liverpool, L3 2ET, UK;

m.a.bellis@ljmu.ac.uk

Received 21 August 2013 Revised 26 November 2013 Accepted 27 November 2013 Published Online First 15 January 2014

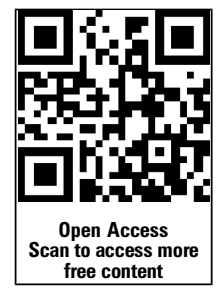

CrossMark

To cite: Hughes $\mathrm{K}$,

Bellis MA, Leckenby $\mathrm{N}$, et al. $J$ Epidemiol Community Health 2014;68:453-456.
ABSTRACT

Background By measuring alcohol retailers' propensity to illegally sell alcohol to young people who appear highly intoxicated, we examine whether UK legislation is effective at preventing health harms resulting from drunk individuals continuing to access alcohol.

Methods 73 randomly selected pubs, bars and nightclubs in a city in North West England were subjected to an alcohol purchase test by pseudo-drunk actors. Observers recorded venue characteristics to identify poorly managed and problematic (PMP) bars.

Results $83.6 \%$ of purchase attempts resulted in a sale of alcohol to a pseudo-intoxicated actor. Alcohol sales increased with the number of PMP markers bars had, yet even in those with no markers, $66.7 \%$ of purchase attempts resulted in a sale. Bar servers often recognised signs of drunkenness in actors, but still served them. In $18 \%$ of alcohol sales, servers attempted to up-sell by suggesting actors purchase double rather than single vodkas.

Conclusions UK law preventing sales of alcohol to drunks is routinely broken in nightlife environments, yet prosecutions are rare. Nightlife drunkenness places enormous burdens on health and health services. Preventing alcohol sales to drunks should be a public health priority, while policy failures on issues, such as alcohol pricing, are revisited.

\section{INTRODUCTION}

Alcohol is a leading risk factor for burden of disease globally, ${ }^{1}$ and the single leading risk factor in young people. ${ }^{2}$ In the UK, alcohol is attributed to more than one in five deaths in those aged 1624 years. ${ }^{3}$ Around two million presentations to English emergency departments (ED) annually are alcohol-related, with patients most likely to be young males, ${ }^{4}$ contributing to a service nearing collapse. ${ }^{5}$ While much of the health harms in young people are accounted for by acute conditions, such as road traffic injury, suicide and violence, ${ }^{3}$ they are also increasingly affected by chronic alcohol-related conditions such as liver disease. ${ }^{6}$ Such increases in alcohol-related mortality and morbidity in younger adults are overshadowing health gains made elsewhere (eg, cervical screening), ${ }^{7}$ yet despite this, public health calls for stronger legislation to curb deaths, injury and illness from alcohol repeatedly lose out to the interests of industry. ${ }^{8}$ Thus, the introduction of a minimum alcohol unit price for England has been withdrawn despite evidence it would reduce premature mortality and antisocial behaviour. ${ }^{9}$ Instead, government has called on local authorities and public services to use existing powers and voluntary agreements with industry to reduce alcohol-related harms. ${ }^{10}$

As statutory partners in reducing crime and disorder and responsible authorities under licensing legislation, ${ }^{11}$ public health professionals are well placed to drive local action to prevent alcoholrelated harm. Moreover, an existing legal power has the potential to reduce drunkenness and its health impacts. UK law prohibits sale of alcohol to anyone already drunk, ${ }^{11}$ yet, convictions for this are extremely rare (three in 2010). ${ }^{12}$ While alcohol retailers insist that sales to drunks do not occur, $70 \%$ of ED attendances between midnight and 5:00 being alcohol-related suggests otherwise. ${ }^{13}$ The impacts of inebriation on those in ED are manifest. However, other consequences, such as domestic violence, child maltreatment and unintentional injuries, occurring when individuals return home, are frequently unrecorded.

Studies outside the UK have tested bar server propensity to over-serve alcohol, ${ }^{14}{ }^{15}$ and used findings to drive enforcement activity, raise server standards and reduce sales to drunks. ${ }^{16}$ Here, we examine whether servers in UK bars sell alcohol to people showing clear signs of intoxication, and consider implications for policy and practice.

\section{METHODS}

The study took place in a city centre in North West England. Four student actors (two male, two female, aged 20-22 years) were recruited through an audition process and trained on acting drunk. Young adult actors were used as test purchasers due to this demographic being the most common users of city centre nightlife environments. A standard act for pseudo-intoxicated alcohol purchase attempts was developed and tested with police (who are legally able to act as expert witnesses for determining drunkenness). The act ensured that a very high level of intoxication was portrayed through key indicators (eg, slurred speech, unsteadiness on feet, difficulty focusing) and that sufficient interaction occurred between actors and bar servers to allow these indicators to be observed.

Venues subjected to alcohol purchase test $(n=73)$ were randomly selected from all $(n=317)$ city centre pubs, bars and nightclubs. Proportionate allocation sampling was used with venues stratified by permitted operating hours (latest closing times through licensing conditions: <midnight, 9\%; midnight $-<2: 00,23 \% ; 2: 00-<4: 0036 \%, 4: 00$ or later $33 \%)$. Venues no longer operating were 
replaced from the same strata. Alcohol purchase attempts were made by two actors and observed by two researchers (May 2013, Wednesday-Sunday nights, 21:00-3:00). Researchers entered venues first to surreptitiously observe purchase attempts and venue characteristics. One actor took the role of the 'drunk' and the other a 'sober' friend. The pseudo-drunk actor stumbled to the bar with the support of the sober friend and using loud, slurred speech asked the price of a vodka and coke. Upon receipt of the price, they fumbled over their purse/wallet and asked for the drink. Actors left the venue immediately if service was refused or shortly after service where this occurred, leaving the drink behind. Observers left a few minutes later. Observers and actors then completed structured observational schedules detailing venue characteristics (eg, crowding, noise levels, presence of door staff) and, for actors, aspects of the alcohol purchase attempt (included in this analysis: service refusal tactics, description of purchase attempt). Observational measures of venue characteristics were drawn from an established tool developed by Graham et $a l^{17}$ and used in previous studies of bar environments. ${ }^{17-19}$

Analysis was undertaken in SPSS (V.20) using $\chi^{2}$ and analysis of variance (ANOVA). To examine relationships between alcohol purchase attempt outcomes and bar characteristics, 10 established markers of poorly managed and problematic (PMP) bars ${ }^{17}$ were drawn from observational data: low levels of seating, cheap alcohol promotions, young bar servers, young clients, high noise levels, crowding, poor lighting, rowdiness, dirtiness and customer intoxication (see table 1). $\chi^{2}$ Analysis identified that these variables were significantly correlated with each other. Thus, the latter six were all significantly related to each other; noise, rowdiness and customer intoxication were also associated with young bar servers; crowding was associated with young clients; and young bar servers and young clients were associated with alcohol promotions. Thus, dichotomised variables were summed into a PMP score for each venue. Ethical approval was obtained from Liverpool John Moores University, and the study adhered to the Declaration of Helsinki.

\section{RESULTS}

Of the 73 purchase attempts, 61 resulted in a sale of alcohol to a pseudo-drunk actor $(83.6 \%$; table 1$)$. Service rates were always high, ranging from $60.0 \%$ on Wednesdays to $94.1 \%$ on Fridays, and from $78.4 \%$ served before midnight to $95.5 \%$ after midnight. Day and time differences were not significant $(p=0.242, p=0.072$, respectively). There were no differences in service outcomes by gender of the pseudo-drunk actor or gender mix of the actor pair. Across the 10 markers of PMP examined, only greater seating provision and older bar staff (most $>25$ years) were individually associated with decreased service to pseudo-drunk actors. However, service rates increased with PMP score. Thus $66.7 \%$ of bars with no PMP markers served alcohol to actors rising to $100 \%$ of bars with $\geq 8$ (table 1). Pseudo-drunk actors were also more likely to be served in bars with door supervisors $(95.1 \%$ served, v $68.8 \%$ in bars without door supervisors, $\mathrm{p}=0.003)$. Most sales occurred without hesitation, despite actors' notes suggesting that servers often recognised drunkenness (see box). Service refusal typically occurred through direct refusal statements (eg, 'sorry, you're too drunk') with other techniques, including use of caring statements, gaining support from other staff, or simply ignoring the actor (see box). Critically, in 18\% of alcohol sales, actors' notes indicated that the bar server attempted to up-sell the actor a double rather than single vodka.
Table 1 Service rates to pseudo-drunk actors in venues with and without markers of poorly managed and problematic (PMP) bars

\begin{tabular}{|c|c|c|c|c|}
\hline PMP markers* & n & Per cent served & $\chi^{2}$ & $p$ Value \\
\hline \multicolumn{5}{|l|}{ Low seating } \\
\hline No & 42 & 76.2 & & \\
\hline Yes & 26 & 96.2 & 4.720 & 0.030 \\
\hline \multicolumn{5}{|c|}{ Cheap drink promotions } \\
\hline No & 39 & 82.1 & & \\
\hline Yes & 34 & 85.3 & 0.139 & 0.709 \\
\hline \multicolumn{5}{|l|}{ Young bar staff } \\
\hline No & 40 & 72.5 & & \\
\hline Yes & 33 & 97.0 & 7.882 & 0.005 \\
\hline \multicolumn{5}{|l|}{ Young customers } \\
\hline No & 56 & 78.6 & & \\
\hline Yes & 14 & 100.0 & 3.621 & 0.057 \\
\hline \multicolumn{5}{|l|}{ Noisy bar } \\
\hline No & 47 & 80.9 & & \\
\hline Yes & 26 & 88.5 & 0.706 & 0.401 \\
\hline \multicolumn{5}{|l|}{ Crowded bar } \\
\hline No & 57 & 82.5 & & \\
\hline Yes & 16 & 87.5 & 0.231 & 0.630 \\
\hline \multicolumn{5}{|l|}{ Poor lighting } \\
\hline No & 62 & 82.3 & & \\
\hline Yes & 11 & 90.9 & 0.509 & 0.476 \\
\hline \multicolumn{5}{|l|}{ Rowdy bar } \\
\hline No & 54 & 79.6 & & \\
\hline Yes & 19 & 94.7 & 2.335 & 0.126 \\
\hline \multicolumn{5}{|l|}{ Dirty bar } \\
\hline No & 53 & 81.1 & & \\
\hline Yes & 20 & 90.0 & 0.831 & 0.362 \\
\hline \multicolumn{5}{|l|}{ Drunk customers } \\
\hline No & 50 & 78.0 & & \\
\hline Yes & 21 & 95.2 & 3.129 & 0.077 \\
\hline \multicolumn{5}{|c|}{ Number of PMP markers } \\
\hline None & 15 & 66.7 & & \\
\hline 1 or 2 & 26 & 80.8 & & \\
\hline 3 or 4 & 10 & 90.0 & & \\
\hline $5-7$ & 16 & 94.1 & & \\
\hline $8-10$ & 5 & 100.0 & 5.491 & 0.019 \\
\hline
\end{tabular}

\section{DISCUSSION}

Alcohol purchase attempts by pseudo-drunk actors in UK bars suggest that the law preventing sale of alcohol to drunks is routinely broken. Over four in five purchase attempts resulted in an alcohol sale despite actors portraying signs of overt drunkenness and bar servers often recognising such signs. Alcohol sales to pseudo-drunk actors increased with number of PMP markers observed in bars, yet even in bars with no such markers, two-thirds of purchase attempts resulted in a sale. Continued provision of alcohol to drunks will increase risks of acute and long-term health and social harms, and consequently, the burdens these place on public services and society.

Although our study focused on one city, a lack of prosecutions for sales to drunks throughout England suggests this is typical of nightlife environments nationally. Across the country, police and licensing authorities work closely with bars to improve standards, yet with the principle objective of reducing 
Box Sample extracts from actors' notes on exchanges with bar servers:

Incidents resulting in bar service

- Bar tender rolled his eyes when he saw me swaying but he still served me.

- Bar tender asked "are you sure you're okay for this?" then served me.

- When bar tender was serving my drink the other bar tender said "You serving her? Look at her eyes" - he said "well, I've poured it now".

- Asked for a drink. They only served doubles. Bar tender said "have you been drinking elsewhere tonight?" I said "yeah" and he said "OK, I'Il give you one but no more tonight, you've had enough".

- Even with [actor's] head on the bar and slurring his words, there was no hesitation for sale. In fact the barman offered him a double.

Incidents resulting in service refusal

- Bar tender touched my arm and said "sorry love, you've had a little too much to drink".

- He asked me if I'd had enough and then went on to say "I don't want you to fall down the stairs". Then as I was leaving he said "be careful and watch out for the step".

- Bar tender poured drink, discussed with another bar maid then said "sorry mate, you're too drunk".

- I was asked if I would stay awake to drink the drink and was then told to leave.

- Server said "Can't serve you honey, would you like a glass of water?"

the antisocial behaviour associated with drunkenness rather than drunkenness itself. ${ }^{20}$ While the health consequences of extreme intoxication are unambiguous, local authorities may be concerned that moves to reduce nightlife alcohol use will damage local night-time economies along with convivial relationships with bars. Equally, with such widespread disregard for the law, police may consider the task of identifying and prosecuting drunken sales overwhelming. However, in other countries, illegal alcohol sales to drunks have been significantly reduced through combined enforcement and awareness-raising based on findings from studies such as this. ${ }^{16}$ Importantly, just a few prosecutions for selling alcohol to drunks in an area could change the norm of flouting the law.

While servers cannot be prosecuted for selling alcohol to people who are only pretending to be drunk, test purchasing is just one mechanism that can identify bars where illegal sales occur in order to target preventative measures. ${ }^{21}$ Such measures include issuing venues with notices warning that they are being observed for breaches of licensing legislation and mandatory staff training to develop service refusal policies and skills. Our finding that venues with door supervisors were more likely to serve alcohol to drunks may reflect confusion among staff about who is responsible for controlling service to drunks, with bar servers believing that individuals permitted into the bar have already been deemed appropriate for service. Ensuring bar servers are aware of their legal responsibilities and the consequences that sales of alcohol to drunks can impose on them personally is crucial. While our study has focused on sales of alcohol to drunks in bars, such sales are also likely to occur in off-licensed premises and the extent of such illicit sales requires examination. Underage alcohol sales, however, have been studied previously, ${ }^{22}$ and test purchasing is now routinely carried out by authorities across the UK. ${ }^{23}$ Here, campaigns such as Challenge $25^{24}$ have supported alcohol servers in on-licensed and off-licensed alcohol outlets to uphold the law. Such campaigns use highly visible signage (eg, posters, badges for staff) transmitting the message that underage sales are not permitted, and that staff will ask any individual appearing under age 25 for proof of age. Similar schemes could be used to raise awareness of laws against sales to drunks, transmit the message that such sales will not be permitted, and provide a mechanism to support staff in service refusal.

Recent policy discussions in the UK and elsewhere have focused on alcohol pricing, with problems of nightlife drunkenness compounded by the consumption of cheap off-licensed alcohol before nights out. ${ }^{25}$ Sales of alcohol to drunks in bars are likely to contribute to such preloading, as they permit individuals who arrive in town and city centres drunk to continue to access alcohol. Effective enforcement of legislation preventing sales of alcohol to drunks, combined with awareness-raising that drunks will not get served, could reduce preloading, and shift social norms away from drunkenness in nightlife settings. In turn, reducing the prevalence of heavy intoxication in nightlife could have major benefits in opening up nightlife to individuals of all ages and beliefs, including those who do not want to socialise in an environment where being drunk is the norm.

While debate on the need for new legislation to reduce alcohol harms continues, more could be done to better enforce existing laws. Leaving the alcohol industry to self-regulate is unlikely to be effective, as a single bar in an area still prepared to serve drunks would benefit from those rejected from compliant bars. Moreover, enforcing no alcohol sales to drunks would impact most heavily on the biggest consumers with nearly $80 \%$ of alcohol consumed by the $30 \%$ heaviest drinkers nationally. ${ }^{26}$ For the same reason, however, it is a highly targeted health measure that would specifically impact on heavy drinkers that get drunk. Any impacts on moderate social drinkers may, in fact, be beneficial; while not changing their drinking behaviours, the reduced presence of heavily intoxicated individuals in nightlife would help reduce moderate drinkers' exposure to the collateral damage caused by drunks. Moreover, reducing attendances at EDs and other health services resulting from drunkenness should improve access for others patients and help alleviate increasing service pressures. Health professionals have been instrumental in instigating change in nightlife management elsewhere (eg, smoking bans, safer glassware). Here also, stopping sales of alcohol to drunks requires advocacy from health professionals who routinely see the damage severe intoxication causes to drunks and those hurt through their actions.

\section{What is already known on this subject?}

Drunkenness is rife in nightlife environments in the UK, and the health and social harms linked to such intoxication place major burdens on individual health, public services and broader society. Despite service of alcohol to people who are drunk being illegal, prosecutions are rare. Studies outside the UK suggest that measuring propensity for servers to sell alcohol to drunks may be an important precursor to better enforcement of legislation, reducing sales to drunks and ultimately reducing the harms associated with alcohol bingeing. 


\section{What this study adds?}

In UK bars, over four in five alcohol purchase attempts by young actors portraying signs of extreme intoxication resulted in a sale of alcohol despite servers often clearly recognising drunkenness. Although service to drunks was more common in poorly managed bars and clubs, it was the norm even in well-managed premises. With policies to prevent alcohol-related harm by increasing alcohol prices failing to be implemented, increased use of legislation preventing sales of alcohol to drunks should be considered a public health priority.

Acknowledgements We thank Orla Clarke, lan Cook, Kat MacDonald and Patrick Moran from Liverpool Screen School and Adam Caris, Kathryn Curran, Dr Gordon Hay, Mark Lawes, Juliette McClymont, Ewan Minter and Dani Sawalhi for their contribution to the study's development and implementation. We are very grateful to colleagues from the police and local authority for their support with the study.

Contributors $\mathrm{KH}$ directed the study, contributed to fieldwork, analysed the data and coauthored the article. MAB conceptualised the study and coauthored the article. NL and ZQ coordinated the study, contributed to field work and edited the manuscript. KHa and OS contributed to study development, field work and manuscript editing. DL recruited and trained actors, contributed to study development and edited the manuscript.

\section{Competing interests None.}

Ethics approval Liverpool John Moores University Research Ethics Committee.

Provenance and peer review Not commissioned; externally peer reviewed.

Data sharing statement The Centre for Public Health will consider all applications for access to original study data on a case by case basis.

Open Access This is an Open Access article distributed in accordance with the Creative Commons Attribution Non Commercial (CC BY-NC 3.0) license, which permits others to distribute, remix, adapt, build upon this work non-commercially, and license their derivative works on different terms, provided the original work is properly cited and the use is non-commercial. See: http://creativecommons.org/ licenses/by-nc/3.0/

\section{REFERENCES}

1 Lim SS, Vos T, Flaxman AD, et al. A comparative risk assessment of burden of disease and injury attributable to 67 risk factors and risk factor clusters in 21 regions, 1990-2010: a systematic analysis for the Global Burden of Disease Study 2010. Lancet 2012;380:2224-60.

2 Gore FM, Bloem PJN, Patton GC, et al. Global burden of disease in young people aged 10-24 years: a systematic analysis. Lancet 2011;377:2093-102.

3 Jones L, Bellis MA, Dedman D, et al. Alcohol-attributable fractions for England: alcohol-attributable mortality and hospital admissions. Liverpool: Centre for Public Health, Liverpool John Moores University, 2008.

4 Hoskins R, Benger J. What is the burden of alcohol-related injuries in an inner city emergency department? Emerg Med J 2013;30:e21.
5 House of Commons Health Select Committee. Health Committee - second report: urgent and emergency services. 2013. http://www.publications.parliament.uk/pa/ cm201314/cmselect/cmhealth/171/17102.htm (accessed 21 Aug 2013).

6 Sheron N, Olsen N, Gilmore I. An evidence-based alcohol policy. Gut 2008; 57:1341-4.

7 Murray CJ, Richards MA, Newton JN, et al. UK health performance: findings of the Global Burden of Disease Study 2010. Lancet 2013;381:997-1020.

8 McCambridge J, Hawkins B, Holden C. Industry use of evidence to influence alcohol policy: a case study of submissions to the 2008 Scottish government consultation. PLoS Med 2013;10:e1001431.

9 Meng Y, Brennan A, Holmes J, et al. Modelled income group-specific impacts of alcohol minimum unit pricing in England in 2014/15: policy appraisals using new developments to the Sheffield Alcohol Policy Model (v2.5). Sheffield: University of Sheffield, 2013.

10 Home Office. Next steps following the consultation on delivering the Government's alcohol strategy. London: Home Office, 2013.

11 Parliament of the United Kingdom. Licensing Act 2003. http://www.legislation.gov. uk/ukpga/2003/17/contents (accessed 21 Aug 2013).

12 HM Government. The government's alcohol strategy. Norwich: The Stationery Office Limited, 2012.

13 Drummond C, Phillips T, Coulton S, et al. National prevalence survey of alcohol-related attendances at accident and emergency departments in England. Alcohol Clin Exp Res 2005;29:36A.

14 Lenk KM, Toomey TL, Erickson DJ. Propensity of alcohol establishments to sell to obviously intoxicated patrons. Alcohol Clin Exp Res 2006;30:1194-9.

15 Andreasson S, Lindewald B, Rehnman C. Over-serving patrons in licensed premises in Stockholm. Addiction 2000;95:359-63.

16 Wallin E, Gripenberg J, Andreasson S. Overserving at licensed premises in Stockholm: effects of a community action program. J Stud Alcohol 2005; 66:806-14.

17 Graham K, Bernard S, Osgood DW, et al. Bad nights or bad bars? Multi-level analysis of environmental predictors of aggression in late-night large-capacity bars and clubs. Addiction 2006;101:1569-80.

18 Hughes K, Quigg Z, Bellis MA, et al. Drunk and disorganised: relationships between bar characteristics and customer intoxication in European drinking environments. Int J Environ Res Public Health 2012;9:4068-82.

19 Buvik K. How bartenders relate to intoxicated customers. Int J Alcohol Drug Res 2013;4:1-6.

20 Bellis MA, Hughes K. Getting drunk safely? Night-life policy in the UK and its public health consequences. Drug Alcohol Rev 2011;30:536-45.

21 Graham K, Miller P, Chikritzhs T, et al. Reducing intoxication among bar patrons: some lessons from prevention of drinking and driving. Addiction 2013; Epub ahead of print. doi:10.111/add./12247.

22 Willner P, Hart K, Binmore J, et al. Alcohol sales to underage adolescents: an unobtrusive observational field study and evaluation of a police intervention. Addiction 2000;9:1373-88.

23 LACORS. A practical guide to test purchasing. 2010. http://www.lacors.gov.uk/ lacors/upload/23992.pdf (accessed 20 Nov 2013).

24 Home Office. Selling alcohol responsibly: good practice examples from the alcohol retail and hospitality industries. London: Home Office, 2010.

25 Hughes $\mathrm{K}$, Anderson Z, Morleo M, et al. Alcohol, nightlife and violence: the relative contributions of drinking before and during nights out to negative health and criminal justice outcomes. Addiction 2008; 103:60-5.

26 Booth A, Meier P, Stockwell T, et al. Independent review of the effects of alcohol pricing and promotion. Part A: systematic reviews. Sheffield: University of Sheffield, 2008. 